\title{
EFFECT OF EDM ASSISTED BY MAGNETIC FIELD ON SURFACE INTEGRITY OF ARMOURED STEEL
}

\author{
T. A. El-Taweel ${ }^{1}$, A. R. El-Desouky ${ }^{1}$ and W. M. Farouk ${ }^{2}$ \\ ${ }^{1}$ Mechanical Design and Production Engineering Department \\ Faculty of Engineering, Minoufiya University, Shebin El-Kom, Egypt \\ ${ }^{2}$ Mechanical Engineering Department, Faculty of Engineering, \\ Helwan University, Helwan, Egypt
}

\begin{abstract}
In the present study, EDM assisted by magnetic field process is proposed. The effect of EDM assisted by magnetic field process parameters on the surface integrity of armoured steel (HV500) has been studied. The response surface methodology (RSM) is employed to identify the effect of EDM machining parameters, i.e., peak current, magnetic flux density, duty factor and flushing pressure, on the surface integrity of machined component. The process performance criterion such as surface roughness $(\mathrm{Ra})$ was evaluated. RSM was employed to develop the experimental model. Experiments performed on a newly designed experimental setup developed in the laboratory. The surface integrity was also explored by the scanning electron microscope (SEM) and micro-hardness testing to evaluate the effects of the EDM process assisted by magnetic field. This paper studies the topography of the ED-machined surface, the size and the amount of cracks on the surface layer. Hardness variation in the depth of the defective layer, when machining with and without magnetic field of the copper and graphite electrodes under different machining conditions has also been tested. SEM, micro-hardness testing results together with surface topography investigation showed that EDM assisted by magnetic field has the applicability to improve surface integrity.

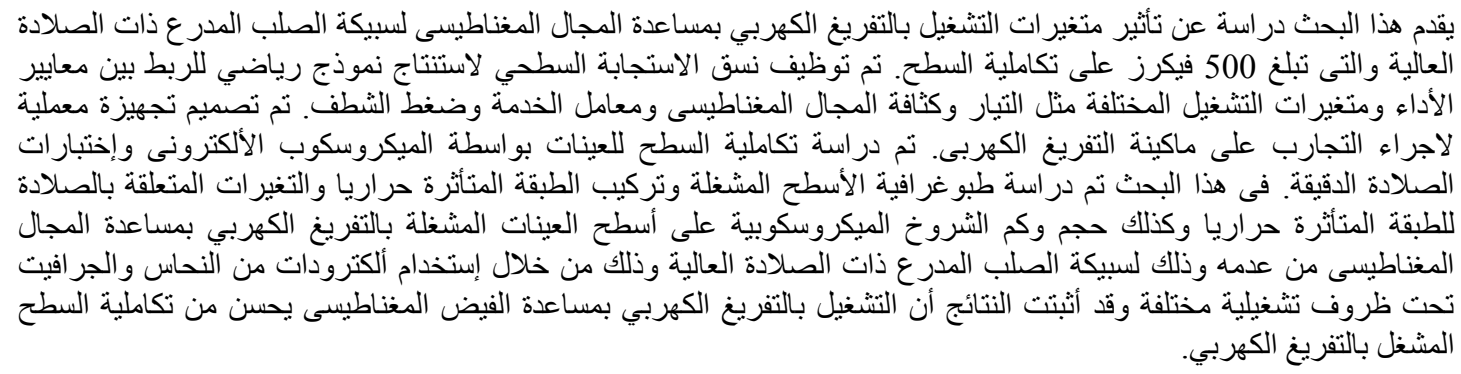

Keywords: EDM, Armoured Steel Alloy (HV500), Surface Integrity, Scanning Electron Microscope (SEM), Micro-hardness, Response Surface Methodology (RSM).

\section{INTRODUCTION}

The surface integrity of a machined surface is becoming increasingly important to satisfying the increasing demands of sophisticated components performance, durability, and reliability. Surface integrity is defined as the inherent or enhanced condition of surface produced in a machining or other surface generating operation. The nature of the surface layer has been found in many cases to have a strong influence on the mechanical properties of the part. This association is more pronounced in some materials and under certain machining operations [1].
Armoured steel is one of the widely used materials in engineering applications, especially in military applications, with expected growing demand in the future. With its exceptional hardness, wear resistance and high mechanical strength, it is becoming very desirable for a number of applications. However, these characteristics cause the machining of armoured steel to be very difficult and expensive. To overcome technical difficulties in machining of this material, nontraditional machining methods are employed, among which electrical discharge machining (EDM) has been the most suitable. 
In the EDM process, a very small area of the closely spaced surfaces of the electrodes is heated, melted and vaporized, and there is no direct physical contact between the electrodes. Therefore, no direct mechanical forces are exchanged between the workpiece and the tool. This process has the capability of machining any electrically conductive hard material including armoured steel regardless of their hardness. On the other hand, whenever EDM process is employed in machining of advanced materials, much attention should be paid to the machined surface characteristics, as it may alter completely the mechanical properties and fatigue life of the base material. The types of surface alterations are associated with generation of recast superficial layer, recrystallization, phase transformations, intergranular attack, preferential removal of micro-constituents, depletion of low melting point contents, joining of high melting point compositions, residual stress creation, hardening and brittling of the surface layer and as a result micro and macro- cracking of the surface $[1,2]$. Due to these deficiencies and poor surface integrity, EDM has been avoided by aerospace industry for a long time. Diminishing or removal of the influence of the above layers or zones can be achieved either by polishing, etching or by heat treatment.

Alternatively, burnishing or shot peening could be employed in order to impose a compressive residual stress regime. It must be considered that, such processes are, however, supplementary and will increase manufacturing cost and time. Since these operations are very expensive, it is advisable to overcome the difficulties by employing new machining methods, among which EDM assisted by magnetic field claims its share.

Bruijn et al. [3] investigated the effect of magnetic field on the gap cleaning and indicated that the magnetic field can improve gap cleaning. Nevertheless, there are few relative reports associated with the magnetic force used in the EDM process to improve the machining characteristics. The ability to expel the machining debris was a crucial factor for maintaining the stability of EDM progress, so the machining efficiency and the quality of surface integrity associated with an EDM process were directly affected by this ability.

Several researchers have investigated the effects of dielectric flush and ejection mechanisms of machining debris for EDM [5-9]. Rajurkar et al. [5] proposed a debris ejection mechanism through the analysis of shock waves resulted from electrical discharge. Masuzawa et al. [6] investigated a dynamic jet flushing method, and their experimental results showed that the sweeping jet method was superior to conventional fixed jet flushing. Cetin et al. [8] investigated the effect of electrode jump height on the machining speed of EDM and proposed a debris exclusion model for improving the expelling of machining debris to prevent the debris clogged in the machining gap. Several researchers carried out their studies by providing ultrasonic vibration through electrodes (either tool electrode or workpiece electrode), as well as dielectric fluid to solve the debris accumulation and to maintain the stability of the machining progress [9-13]. Their research reported that preventing the debris accumulated in the machining gap had the important benefit for promoting machining efficiency. Furthermore, the added abrasives that acted as ultrasonic media for the combined process of EDM with ultrasonic machining (USM) can be regarded as the surface strengthening agents transferred to the machined surface through ionization of discharge column during the process [14]. The combined process of EDM with USM had the potential to prevent debris accumulation, to improve machining efficiency, and to modify the machined surface. However, to design an USM equipment for machining large area was intensively constricted, and the degree of tool fastened on the USM system was vigorous. Therefore, to construct the combined process of EDM with USM for various workpiece dimensions with convenient, effective and economic features is a complicated work and a real challenge. Especially, when using the EDM process to manufacture a mold with a large projection area is urgently required in the mold making industry recently [13]. The ability to expel machining debris in such situation was relatively difficult during EDM, so the machining problem needed intensive efforts to develop an innovative technique to overcome this challenge.

In the present investigation, a magnetic force device was proposed to attach an EDM machine to develop an innovative process. Using this device, a series of experiments have been conducted to explore the effects of the main machining parameters on surface integrity like surface topography, surface roughness parameter, such as Ra, composition, microcracks and microhardness.

\section{EXPERIMENTAL DETAILS}

\subsection{Experimental Procedure and Measurements}

In the present study, Ra has been considered for evaluating the machining performance. $\mathrm{Ra}$ is correlated with input machining parameters such as peak current (Ip), magnetic flux density $(\beta)$, duty factor $(D)$ and 
dielectric fluid pressure $(p)$. The experiments were conducted on an AGETRON advance (USA) diesinking EDM machine. Figures 1 and 2 show photograph for the test rig and schematically diagram for the action of machining debris driven by magnetic force during the EDM process assisted by magnetic field. The electrodes materials were made of copper and graphite with dimensions of $9 \times 9 \times 28 \mathrm{~mm}^{3}$. The workpiece material used in these experiments was high performance armoured steel with dimensions of $8 \times 10 \times 16 \mathrm{~mm}^{3}$. Table 1 shows the chemical composition of armoured steel. The selection of this material was made taking into account its wide range of applications in military and automotive industries. It can be classified as a difficult-to-cut material, not suitable for traditional machining. During machining, commercial kerosene was circulated as the dielectric fluid with a side flushing technique. The machining time for each experiment was variable and related to the machining conditions and fixed parameters which are listed in Table 2. These were chosen through reviews of experience, literature surveys, and some preliminary tests [1-3].

In this process, the magnetic flux density of $0-0.1 \mathrm{~T}$ was used in the working gap of EDM process. Two solenoid coils were connected in series to generate the electromagnetic field. Winding copper wire of $0.13 \mathrm{~mm}$ diameter was surrounded around the core to form the solenoid. Soft iron with a high relative magnetic permeability was used for both the magnetic cores and the poles. The magnetic flux density in the working gap was varied by changing the input current to the electromagnet and the magnetic field was kept orthogonal to the electric field. The workpiece and tool electrode were cleaned by acetone before and after each experiment and then dried in a dryer furnace.

The magnetic flux intensity was calculated as follows:

$$
H=N I / L,(\text { A.turn }) / m
$$

where:

H: Magnetic flux intensity, (A. turn) / m.

I: Current A.

$\mathrm{N}$ : Number of turns.

L: Length of magnetic core $\mathrm{m}$.

Also, the magnetic flux density was calculated

$$
\begin{gathered}
\beta=\mu \mathrm{H},(\text { Tesla) } \\
\mu=\mu_{\mathrm{O}}{ }_{\mathrm{r}}
\end{gathered}
$$

Where,

$$
\begin{aligned}
& \mu_{\mathrm{O}}=4 \pi \times 10^{-7}, \mu_{\mathrm{r}}=1, \text { for free space } \\
& \beta \text { : Magnetic flux density, Tesla. }
\end{aligned}
$$

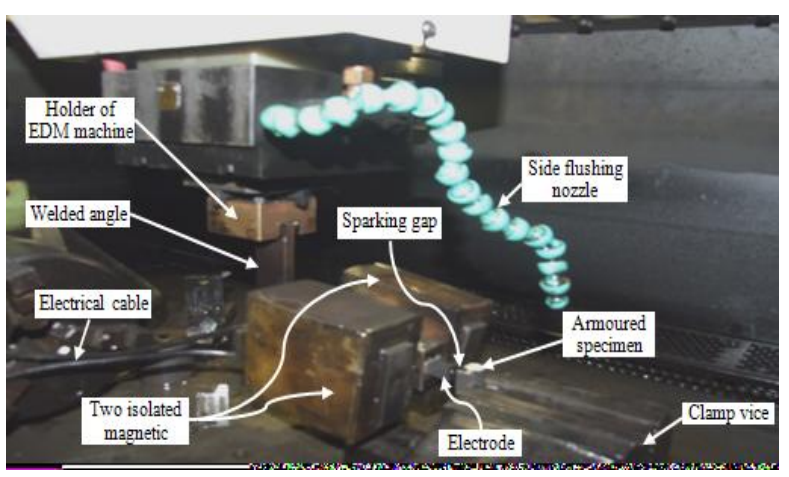

Fig. 1 Photograph of magnetic field test rig

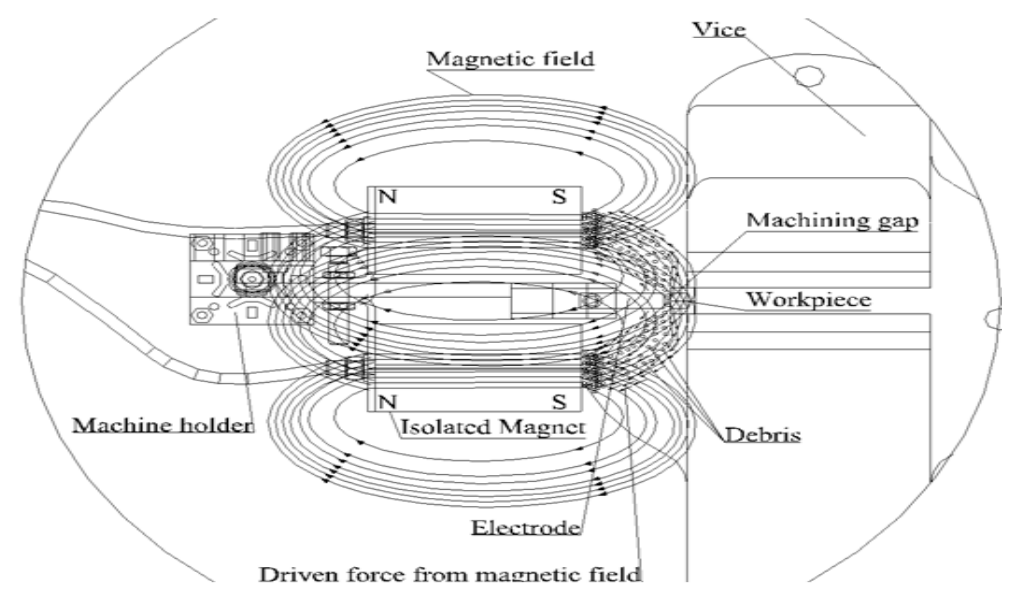

Fig. 2 Schematic diagram of the debris driven by the magnetic force in machining gap 
Table 1, Chemical composition of armoured steel (wt \%)

\begin{tabular}{|c|c|c|c|c|c|c|c|}
\hline $\mathrm{C} \%$ & $\mathrm{Si} \%$ & $\mathrm{Mn} \%$ & $\mathrm{P} \%$ & $\mathrm{~S} \%$ & $\mathrm{Cr} \%$ & $\mathrm{Mo} \%$ & $\mathrm{Fe} \%$ \\
\hline 0.4381 & 0.251 & 0.912 & 0.0073 & $<0.0005$ & 0.4780 & 0.3883 & 96.27 \\
\hline $\mathrm{Ni} \%$ & $\mathrm{Al} \%$ & $\mathrm{Co} \%$ & $\mathrm{Cu} \%$ & $\mathrm{~V} \%$ & $\mathrm{~W} \%$ & $\mathrm{Sn} \%$ & \\
\hline 0.935 & 0.0482 & 0.0116 & 0.2220 & 0.0389 & $<0.0050$ & $<0.0010$ & \\
\hline
\end{tabular}

The value of current for two magnetic core with length $180 \mathrm{~mm}$ was equal to 1.08 ampere at a voltage of 220 volts and the number of turns for coiled copper wire around the magnetic core for test rig was 12000 turns. By applying equations 1 and 2, the values of magnetic flux intensity and magnetic flux density were calculated.

The duty factor was calculated using the following formula:

$$
\text { Duty factor }(D)=\frac{\text { pulse on }- \text { time }}{(\text { pulse on - time })+(\text { pulse off }- \text { time })}
$$

The range of duty factor on an AGETRON advance (USA) die-sinking EDM machine was ranging between $0.142 \mu \mathrm{s}$ and $0.975 \mu \mathrm{s}$, the range of voltage for magnetic flux was ranging between 0 volts and 220 volts and the range of magnetic flux density was ranging between 0 Tesla and 0.1 Tesla. The surface roughness tester, surf test SJ.201P/MMitutoyo, (Japan) was used to measure the average arithmetic mean surface roughness (Ra) for each EDM machined specimen. Each surface roughness value was the average of four measurements. This instrument is adjusted to the following values; measuring length $(50 \mathrm{~mm})$, measuring speed $(0.5 \mathrm{~mm} / \mathrm{s})$ and sampling length $(0.8 \mathrm{~mm})$.

Table 2, EDM machining conditions

\begin{tabular}{|l|l|}
\hline Working condition & Value \\
\hline Workpiece material & Armoured steel \\
\hline Tool Polarity & Negative \\
\hline Electrode material & Copper, Graphite \\
\hline Peak Current, Ip & 20-60 A \\
\hline Magnetic flux density, $\beta$ & $0-0.1$ Tesla \\
\hline Duty factor & $0.142-0.975$ \\
\hline Dielectric fluid pressure, P & $0-1.2$ bar \\
\hline Dielectric fluid & Kerosene \\
\hline Dielectric flushing & Side flushing \\
\hline Depth of cut & $3 \mathrm{~mm}$ \\
\hline
\end{tabular}

The micro hardness tester machine was a Zwick 3212 micro hardness tester with video camera, (Japan) in a central laboratory for elemental and isotopic analysis using a load of $75 \mathrm{~g}$ and an indentation time of ten seconds was used in this investigation.
Also, the recast layer at the cross section of the machined specimens was examined. A low vacuum technique allows observation and analysis for any insulator specimen without conductive coating. The JEOL-5410 (Japan) scanning electron microscope (England) was also used.

\subsection{Experimental Design}

Response surface methodology (RSM) is an interaction of mathematical and statistical techniques for modelling and optimizing the response variable models involving quantitative independent variables [15-20]. In the present work, the range of the Peak current (Ip), Magnetic flux density $(\beta)$, Duty factor $(D)$, Dielectric fluid pressure $(P)$ settings have been selected after performing some pilot experiments. Actual and coded values of the input process parameters have been listed in Table 3. Experiments have been carried out according to the experimental plan based on central composite rotatable second order design (CCD) [17-19]. The Design of experiment matrix showing actual values of the input process parameters is shown in Table 4.

\section{RESULTS AND DISCUSSION}

\subsection{Effect of Machining Parameters on Ra Using Copper Electrode}

It is practically impossible to produce the geometry of engineering products perfectly in agreement with ideal dimensions of the component. $\mathrm{Ra}$ is a measure of the texture of a machined surface quality. The definition of $\mathrm{Ra}$ is the arithmetic mean of the absolute values of the profile deviation from the mean line and it is defined over the entire evaluation length. The effect of input parameters on the value of $\mathrm{Ra}$ has been evaluated using the results in Table 4 . The mathematical model of surface roughness (Ra) when using copper electrode can be expressed as follows:

$\mathrm{Ra}_{\mathrm{cu}}=2.60+0.67 \mathrm{X}_{1}-0.13 \mathrm{X}_{2}-0.23 \mathrm{X}_{3}-0.17 \mathrm{X}_{4^{-}}$ $0.058 \mathrm{X}_{1}^{2}+0.026 \mathrm{X}_{2}^{2}-0.29 \mathrm{X}_{3}^{2}+0.081 \mathrm{X}_{4}^{2}-0.033 \mathrm{X}_{1} \mathrm{X}_{2}-$ $0.12 \mathrm{X}_{1} \mathrm{X}_{3}-0.21 \mathrm{X}_{1} \mathrm{X}_{4}+0.052 \mathrm{X}_{2} \mathrm{X}_{3}-0.15 \mathrm{X}_{2} \mathrm{X}_{4^{-}}$ $0.097 \mathrm{X}_{3} \mathrm{X}_{4}$ 
Table 3, Coded and actual values of the input parameters

\begin{tabular}{|l|c|c|c|c|c|c|}
\hline \multirow{2}{*}{ Input parameters } & \multirow{2}{*}{ Symbol } & \multicolumn{6}{|c|}{ Levels } \\
\cline { 3 - 7 } & & -1 & -1 & 0 & +1 & +2 \\
\hline Peak current (Ip), A & $\mathrm{X} 1$ & 20 & 30 & 40 & 50 & 60 \\
\hline Magnetic flux density ( $\beta$ ), Tesla & $\mathrm{X} 2$ & 0 & 0.025 & 0.05 & 0.075 & 0.1 \\
\hline Duty factor (D) & $\mathrm{X} 3$ & 0.15 & 0.34 & 0.53 & 0.72 & 0.91 \\
\hline Dielectric fluid pressure (P), bar & $\mathrm{X} 4$ & 0.4 & 0.6 & 0.8 & 1 & 1.2 \\
\hline
\end{tabular}

Table 4, Experimental design matrix and results for copper and graphite electrodes

\begin{tabular}{|c|c|c|c|c|c|c|}
\hline Exp. & \multicolumn{3}{|c|}{ Input parameters } & \multicolumn{2}{|c|}{ Experimental results } \\
\cline { 2 - 7 } No. & $I p, A$ & $B$, Tesla & $D$ & $P$, bar & $\mathrm{Ra}_{\mathrm{Cu}}, \mu \mathrm{m}$ & $\mathrm{Ra}_{\mathrm{Gr}}, \mu \mathrm{m}$ \\
\hline 1 & 30 & 0.025 & 0.34 & 0.6 & 1.96 & 6.98 \\
2 & 50 & 0.025 & 0.34 & 0.6 & 3.79 & 6.02 \\
3 & 30 & 0.075 & 0.34 & 0.6 & 1.34 & 6.81 \\
4 & 50 & 0.075 & 0.34 & 0.6 & 3.82 & 5.94 \\
5 & 30 & 0.025 & 0.72 & 0.6 & 1.58 & 5.5 \\
6 & 50 & 0.025 & 0.72 & 0.6 & 3.09 & 6.46 \\
7 & 30 & 0.075 & 0.72 & 0.6 & 1.9 & 7.33 \\
8 & 50 & 0.075 & 0.72 & 0.6 & 2.66 & 6.902 \\
9 & 30 & 0.025 & 0.34 & 1 & 2.54 & 6.89 \\
10 & 50 & 0.025 & 0.34 & 1 & 3.2 & 8.07 \\
11 & 30 & 0.075 & 0.34 & 1 & 1.58 & 5.89 \\
12 & 50 & 0.075 & 0.34 & 1 & 2.45 & 6.66 \\
13 & 30 & 0.025 & 0.72 & 1 & 1.39 & 6.4 \\
14 & 50 & 0.025 & 0.72 & 1 & 2.56 & 7.63 \\
15 & 30 & 0.075 & 0.72 & 1 & 1.03 & 7.27 \\
16 & 50 & 0.075 & 0.72 & 1 & 1.56 & 8.23 \\
17 & 20 & 0.05 & 0.53 & 0.8 & 0.98 & 5.87 \\
18 & 60 & 0.05 & 0.53 & 0.8 & 4.11 & 6.67 \\
19 & 40 & 0 & 0.53 & 0.8 & 2.74 & 7.34 \\
20 & 40 & 0.1 & 0.53 & 0.8 & 3.016 & 7.98 \\
21 & 40 & 0.05 & 0.15 & 0.8 & 1.79 & 4.69 \\
22 & 40 & 0.05 & 0.91 & 0.8 & 1.47 & 6.234 \\
23 & 40 & 0.05 & 0.53 & 0.4 & 3.16 & 7.591 \\
24 & 40 & 0.05 & 0.53 & 1.2 & 3.04 & 7.41 \\
25 & 40 & 0.05 & 0.53 & 0.8 & 2.41 & 6.69 \\
26 & 40 & 0.05 & 0.53 & 0.8 & 2.88 & 7.32 \\
27 & 40 & 0.05 & 0.53 & 0.8 & 2.22 & 7.24 \\
28 & 40 & 0.05 & 0.53 & 0.8 & 2.01 & 7.14 \\
29 & 40 & 0.05 & 0.53 & 0.8 & 3.5 & 6.28 \\
30 & 40 & 0.05 & 0.53 & 0.8 & 2.59 & 6.25 \\
31 & 40 & 0.05 & 0.53 & 0.8 & 3.1 & 6.50 \\
\hline
\end{tabular}

Figures (3-5) show the estimated response of Ra in a relation to the peak current at various values of magnetic flux density, duty factor and dielectric fluid pressure using copper electrodes. It is shown that any increase in the peak current leads to the increase of $\mathrm{Ra}$. This result is due to the huge discharge energy that would be delivered into the machining zone within a single pulse. When the peak current was set at a high level, the machined surface presented a larger crater size and Ra will be increased [20].

Figures (3-5) indicate the effect of the magnetic flux density on the $\mathrm{Ra}$ at various values of duty factor, 
dielectric fluid pressure and peak current. Generally, an increase in the magnetic flux density leads to a decrease in the Ra. This result is due to the un expelled debris accumulated on the machining zone would result in abnormal discharge and would remelt machined surface, so the machined surface would be damaged and the recast layer would be thickened. As a result, the Ra obtained by conventional EDM was higher than that by the magnetic field assisted EDM. The machining debris would be driven by the magnetic force to prevent their clogging in the machining gap, and the debris would also be expelled from the machining gap more completely and quickly. Therefore, the probability of abnormal discharge was reduced and the thickness of the recast layer on which the remelted debris to be deposited was also diminished. Therefore, the $\mathrm{Ra}$ was improved due to the presence of the generated magnetic field [20].

The effect of the duty factor on $\mathrm{Ra}$ at various values of dielectric was assessed from Fig. 4. It is noted that from these figure, $\mathrm{Ra}$ increases greatly with the increase of duty factor. This is due to the improvement of the dielectric fluid pressure around the machining area and also the improvement of peak current. The pulse duration will be increased when the duty factor is increased and hence there is a large heat discharge energy during the single pulse and this will lead a big and large craters and craters interaction when the pulses are repeated and hence the surface of the machining area becomes rougher and $\mathrm{Ra}$ increases. This result is agreement with that obtained previously by [20].

The relationship between the dielectric fluid pressure and $\mathrm{Ra}$ is presented in Fig. 5 at various values of duty factors, magnetic flux density and peak current. It has been observed that the surface roughness increases greatly with the increasing of the dielectric fluid pressure. This is due to the hydrodynamic effect which is generated from the high values of dielectric fluid pressure and affecting on the surface of machined area. So, $\mathrm{Ra}$ becomes poor and rough, and suitable value of dielectric fluid pressure is needed for machining by EDM assisted by magnetic field. [20].

\subsection{Effect of Machining Parameters on Ra Using Graphite Electrode}

The surface texture in EDM is characterized by the typical discharge craters. The surface roughness is therefore mainly determined by the electric pulse parameters: discharge current, discharge duration and polarity. The desired surface roughness of a part is dependent of its application. A shiny surface with a very low roughness is not always needed or wanted.

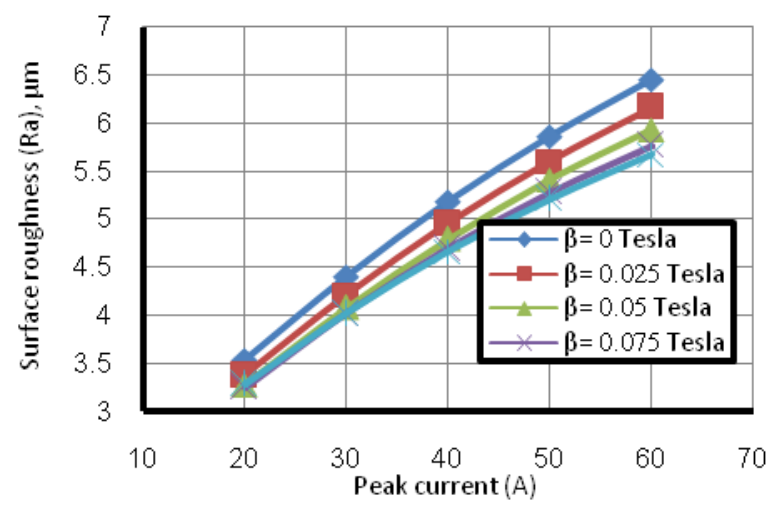

Fig. 3 Effect of the peak current on Ra at various magnetic flux densities ( $D=0.53, P=0.8$ bar, copper elect.)

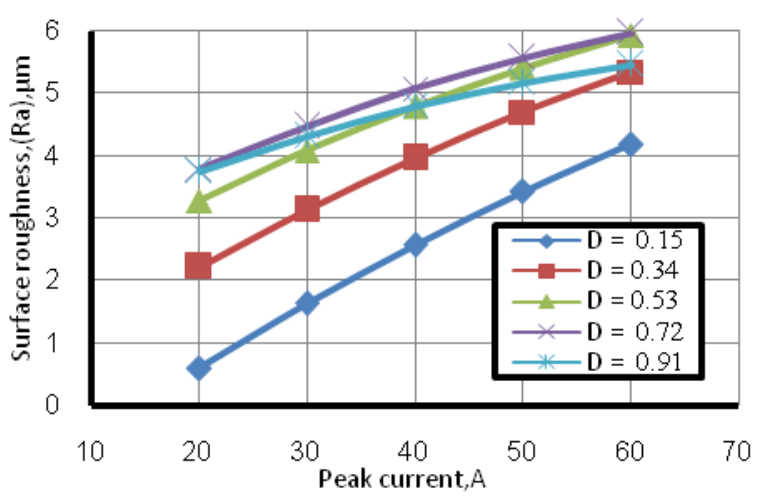

Fig. 4 Effect of the peak current on Ra at various duty factors $(\beta=0.05$ Tesla, $P=0.8$ bar, copper elect. $)$

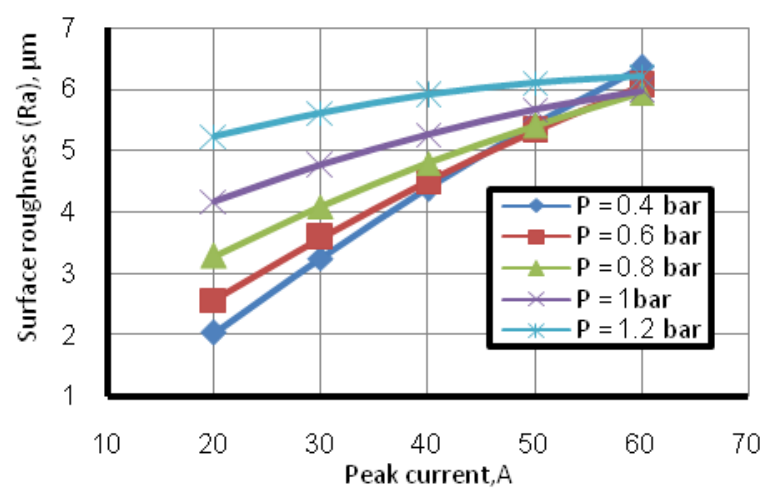

Fig. 5 Effect of the peak current on Ra at various dielectric fluid pressures ( $\beta=0.05$ Tesla, $D=0.8$, copper elect, )

Plastic injection moulds for many consumer products for example, require a mat and somewhat rough surface, which is easily obtainable by sinking EDM. For some applications, EDM is therefore even applied as a surface texturing process, rather than a material removal process. The effect of input parameters on value of surface roughness $(\mathrm{Ra})$ has been evaluated using the results in Table 4. The 
mathematical model of surface roughness $(\mathrm{Ra})$ when using graphite electrode can be expressed as follows:

$\mathrm{Ra}_{\mathrm{Gr}}=6.82+0.19 \mathrm{X}_{1}+0.098 \mathrm{X}_{2}+0.23 \mathrm{X}_{3}+0.20 \mathrm{X}_{4}-0.12 \mathrm{X}_{1}^{2}+$ $0.22 \mathrm{X}_{2}^{2}-0.32 \mathrm{X}_{3}^{2}+0.18 \mathrm{X}_{4}^{2}-0.12 \mathrm{X}_{1} \mathrm{X}_{2}+0.16 \mathrm{X}_{1} \mathrm{X}_{3}+$

$0.34 \mathrm{X}_{1} \mathrm{X}_{4}+0.40 \mathrm{X}_{2} \mathrm{X}_{3}-0.19 \mathrm{X}_{2} \mathrm{X}_{4}+0.099 \mathrm{X}_{3} \mathrm{X}_{4}$

Figures (6-8) exhibit the influence of the peak current on the $\mathrm{Ra}$ at various values of magnetic flux density, duty factor and dielectric fluid pressure. Generally, the Ra increases with the increase of peak current expected at the high levels of magnetic flux density, low levels of duty factor and low levels of dielectric fluid pressure. This is due to the huge discharge energy delivered into the machining zone within a single pulse. Also, an increase in the discharge current means an increase in the discharge heat which melts and evaporates the material of workpiece. The net result is the separation of high number of the workpiece material grains which leads to a high values of $\mathrm{Ra}$. It is believed that the increase in discharge current causes an increase in the discharge heat energy at the point where the discharge takes place. At this point, a pool of molten material is formed and overheated. The overheated molten material evaporates, forming gas bubbles that explode when the discharge ceases; taking molten metal material away. The result is the formation of a crater. Successive discharges that have a random nature will result in the formation of overlapped craters, pockmarks, and chimney. The diameter and depth of the crater depend on the discharge heat energy; or in other words the discharge current and pulse duration time. It can be seen that the increase in pulse duration results in a more increase in $\mathrm{Ra}$ than that with the increase in discharge current [21-22]. The increase in pulse duration allows gas bubbles to increase in number and to grow larger as a result of applying the heat energy for longer time. When the discharge ceases these big gas bubbles will collapse containing higher pressure energy. The gas bubbles will explode liberating stronger dynamic ejecting and splashing forces. The result is more deeper and irregular cavities which increase the surface roughness. The unexploded gas bubbles forms bigger pockmarks which also increase $\mathrm{Ra}$ and irregularities. In addition, bombing of the workpiece surface with ions, which tear surface particles for longer time, increase Ra. Also, longer pulse durations increase the spark gap and create arcing conditions which increase the surface damage [22].

Figure 6 indicates the effect of magnetic flux density on $\mathrm{Ra}$ at various values of peak current. Furthermore, as mentioned before the case of copper electrode, generally, an increase in the magnetic flux density leads to a decrease in Ra. However, in case of graphite electrode, $\mathrm{Ra}$ decreases and then after magnetic flux density reached 0.05 Tesla, it becomes is slightly increases especially at high level values as well as low level values of dielectric fluid pressure. The biggest value for $\mathrm{Ra}$ is equal to $8 \mu \mathrm{m}$ at $\beta=0$ Tesla, and $\mathrm{Ip}=60 \mathrm{~A}$ as shown in Fig. 6. This result is due to the arcing phenomena which make the magnetic flux density not effective at high levels of duty factor and low level values of dielectric fluid pressure.

The effect of the duty factor on the Ra at various values of peak current is demonstrated in Fig. 7. It is noted that $\mathrm{Ra}$ increases with duty factor until a value of 0.5 and then the Ra decreases slightly but still in large values when compared with the initial values. This is due to the improvement of the dielectric fluid pressure and peak current. The pulse energy increases as peak current increases and hence the on time as duty factor will be increased, this leads to a wide and deep holes and craters on the surface of machining area and hence the $\mathrm{Ra}$ will be increased. The relationship between the duty factor and Ra is nonlinear. As shown in Fig. 7, the $\mathrm{Ra}$ is increases up to a value of 0.5 for the duty factor followed by a decrease in Ra and this is attributed to the improvement of magnetic flux density [20].

Figure 8 shows the effect of dielectric fluid pressure on $\mathrm{Ra}$ at various values of peak current. These figures indicated the same trend as was in the case of copper electrodes. Ra increases greatly with the increasing of the dielectric fluid pressure and this is attributed to the hydrodynamic effect which made turbulence at the machining area and the surface of machined surface becomes filled with big and wide craters, pores and micro cracks and the thickness of recast layer increases, and consequently, Ra increased [22].

Figure 9 shows a comparison between Ra obtained by EDM assisted by magnetic field and conventional EDM by using both copper and graphite electrodes. As shown in this figure, an increase in the magnetic flux density leads to a decrease in the $\mathrm{Ra}$ when copper electrode was used. This result is due to the un expelled debris accumulated on the machining zone that would result in abnormal discharge and would remelt to the machined surface, so the machined surface would be damaged and the recast layer would be thickened. As was illustrated, Ra obtained by conventional EDM was higher than that by the magnetic field assisted EDM. The machining debris would be driven out by the magnetic force to prevent its clogging in the machining gap, and the debris would also be expelled from the machining gap more completely and quickly. Therefore, the probability of abnormal discharge was reduced and the thickness of the recast layer on which the remelted debris to be deposited was also 
diminished. Therefore, Ra was improved due to the presence of an additional magnetic field [20, 21]. However, in case of graphite electrode, Ra decreases and then after magnetic flux density equal to 0.05 Tesla, and started slightly to increase especially at high levels values as well as low level values of dielectric fluid pressure. Also, the biggest value for Ra is equal to $8 \mu \mathrm{m}$ at $\beta=0$ Tesla, and $\mathrm{I}_{\mathrm{p}}=60 \mathrm{~A}$ as shown in Fig. 9 . This result is due to the arcing phenomena which makes the magnetic flux density not effective at high levels of duty factor and low level values of dielectric fluid pressure.

So assisting EDM with magnetic field is a fruitful and beneficial process that leads to a decrease (improve) in surface roughness ( $\mathrm{Ra}$ ) significantly, as compared to that achieved with the conventional EDM of some $17 \%$ when using copper electrodes. Furthermore, an increase in surface roughness (Ra) significantly, as compared to that achieved with the conventional EDM of some $5.22 \%$ when using graphite electrodes.

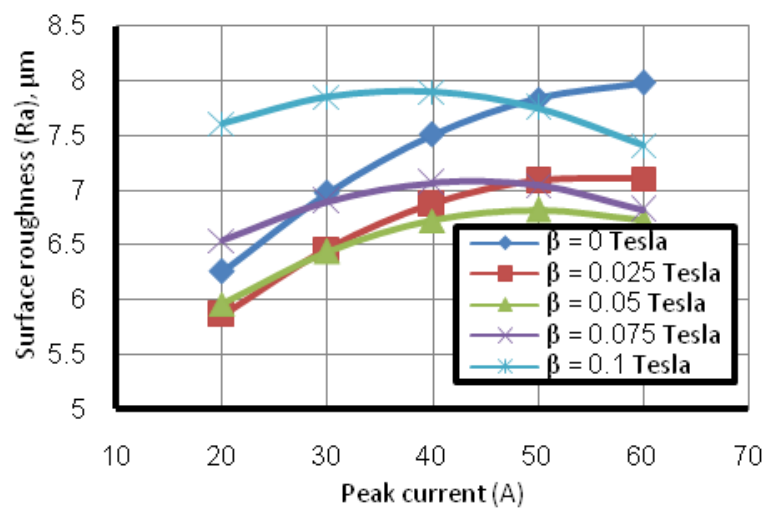

Fig. 6 Effect of the peak current on Ra at various magnetic flux densities $(D=0.53, P=0.8$ bar, graphite elect.)

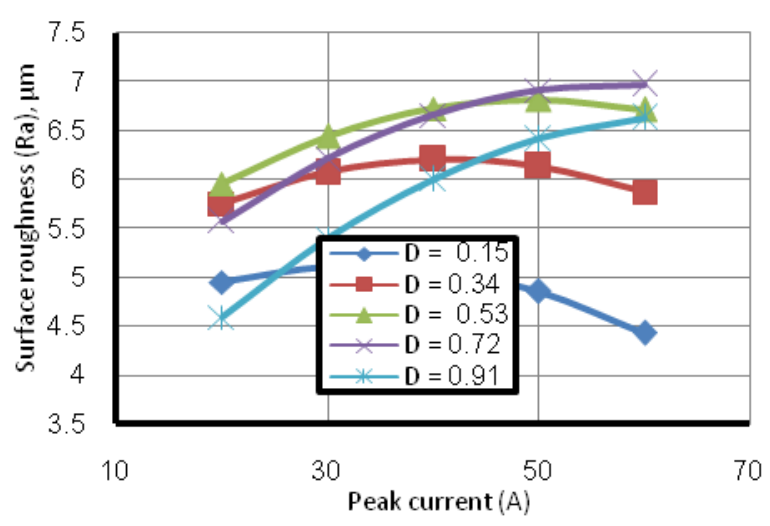

Fig. 7 Effect of the peak current on Ra at various duty factors $(\beta=0.05$ Tesla, $P=0.8$ bar, graphite elect. $)$

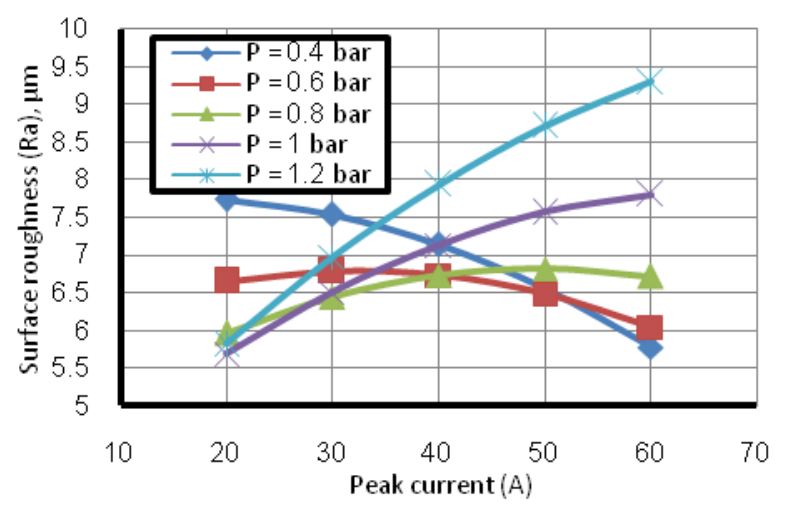

Fig. 8 Effect of the peak current on Ra at various dielectric pressures $(\beta=0.05$ Tesla, $D=0.53$, graphite elect.)

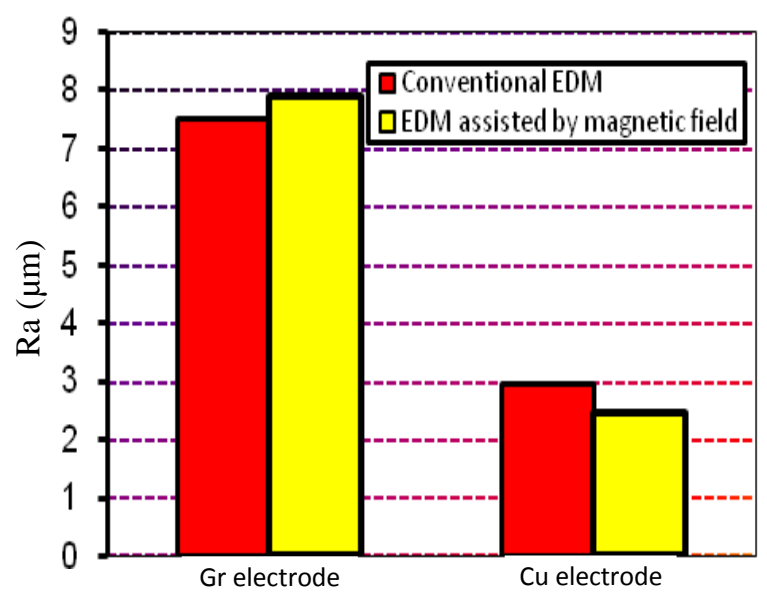

Fig. 9 Comparison of Ra obtained by EDM assisted by magnetic field and conventional EDM at various magnetic flux densities (hold values: $\mathrm{Ip}=40 \mathrm{~A}, \mathrm{D}=0.53$, $\mathrm{P}=0.8$ bar)

\section{Effect of Magnetic Field on Surface Integrity}

\subsection{Microhardness}

The microhardness test was conducted on different depths from the machined surface by using a diamond indenter at a load of $0.5 \mathrm{Kg}$. A typical hardness profile of armoured steel workpiece produced by EDM, is characterized by a zone of very high hardness expanding across the recast layer and the martensitic HAZ. This hard zone can be followed by a tempered zone (in case of pre-hardened armoured steel), that finally evolves towards the hardness of the base material [23].

Figure 10 shows the metallographic structure of the white layer for sinking EDM of armoured steel. The high hardness in the recast layer is neither caused by the presence of amorphous structures, nor by the large 
amounts of martensite. The main reason for the high hardness is the increased amount of dendritic cementite that results from absorption of carbon originating from pyrolysis of the oil dielectric [23].

Figure 11 shows that the distribution of microhardness on the cross-section of a machined armoured steel surface by EDM, using the two tool electrode materials, copper and graphite. This figure clearly show that the maximum microhardness value was obtained close to surface in the two cases of tool electrode materials, and the profiles decrease to the substrate microhardness values. This has been attributed to the rapid quenching and to the increase in the carbon content of the recast layer. It can be seen, that machining by graphite electrodes has higher microhardness than those that machining by copper electrodes. This has been attributed to the higher carbon content in the graphite electrode which migrates effectively to the surface of armoured steel during machining by EDM assisted by magnetic field [15].

The cross sections of EDMed surface using both electrodes were observed by SEM as shown in Fig. 12.

Figure 12 shows that the recast layer (white layer) on the machined surface with the graphite electrodes is rather thick at about $50 \mu \mathrm{m}$, cracks and pores are present in the recast layer. Such a white layer greatly affects die fatigue strength and shortens service life. Damaged surface often removed in a post machining process, greatly increases fabricating time and cost of dies. On the contrary the recast layer is obviously thin (less than $25 \mu \mathrm{m}$ ) when the copper electrodes are used, perhaps because the high temperature during EDM process, a molten pool is formed at the surface of the workpiece and pyrolysis of the dielectric takes place resulting in diffusion carbon in the material. This carbon goes into solution in the molten metal. The iron and the carbon combine to form iron carbides, which solidify in dendritic structures, oriented along the direction of the highest cooling gradient, which is perpendicular to the surface. This phenomenon leads to a significant increase in the microhardness value of the white layer. Based on the findings of the different workers, it was found that, irrespective of the EDM machining conditions used (such as pulse current and pulse on-time), the occurrence of the white layer depends on two main factors, namely, the initial carbon content of the workpiece and the type of dielectric fluid used. If these two conditions are met, then the resulting thickness of the white layer will depend upon the magnitude of the pulse energy (pulse current and/or pulse on-time). Also, the hardness is still higher than for the base material, because of the fine grain structure resulting from high cooling and nucleation rates $[15$, 23].

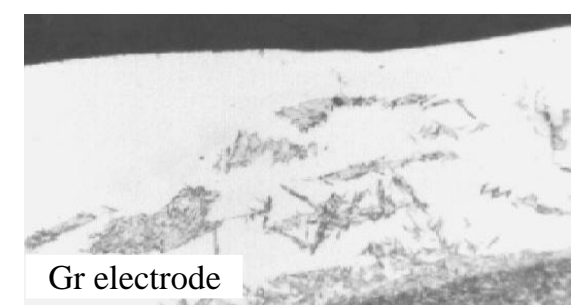

(a) Few martensite spots in the recast layer

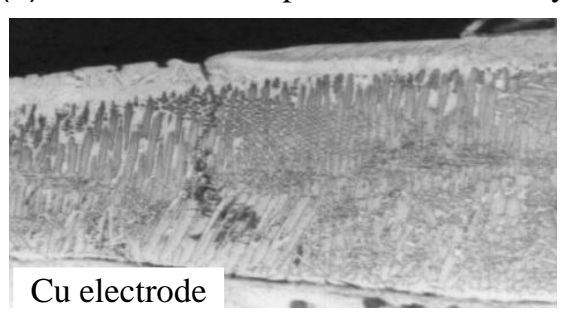

(b) Dentritic structures in the recast layer

Fig. 10 Metallographic structure of the white layer for sinking EDM armoured steel, 200x

\subsection{Microscopic Investigations}

In the present paper, the effects of the EDM assisted by magnetic field process on the surface generated were studied using SEM. Fig. 13 shows SEM micrograph comparison of EDMed surface for armoured steel machined by copper electrode at low peak current of $20 \mathrm{~A}$ and high peak current of $60 \mathrm{~A}$. It can be observed that the actual eroding pattern and overlapping of craters in the case of $60 \mathrm{~A}$, Fig. $13 \mathrm{~b}$, is much wider and deeper than that in the case of $20 \mathrm{~A}$ Fig.13a. Those surfaces produced at higher peak current have a characteristically matte appearance comparing microscopic craters. The craters were partially superimposed, as pools of molten metal have been ejected from a series of overlapping craters [24].

Figures (14-18) show a comparison of SEM micrographs obtained by the magnetic force-assisted EDM and conventional EDM for copper and graphite electrodes at low discharge energy level $\left(\mathrm{I}_{\mathrm{p}}=40 \mathrm{~A}, \mathrm{D}=\right.$ $0.53, \mathrm{P}=0.8$ bar). From these micrographs, the topographies of the machined surfaces were fine under such low discharge energy level due to small discharge craters formed on the machined surface.

In addition, the topography of the machined surface obtained by conventional EDM was bumpier than that by the magnetic force-assisted EDM. Besides, there was more scattered debris attached on the machined surface of conventional EDM. Therefore, the surface roughness of conventional EDM was coarser than that of the magnetic force-assisted EDM. This can be explained based on the fact that the small discharge energy delivered into the machining zone would 
produce numerous minute discharge craters on the machined surface. The debris would not be expelled completely in the conventional EDM due to insufficient impulsive force caused by dielectric explosion at such low level of discharge energy. In contrast, the assisted magnetic force could facilitate and drive the debris expelled from the machining gap. The scattered debris attached on the machined surface was decreased. Thus, the topography of the magnetic force-assisted EDM was even and fine [19].

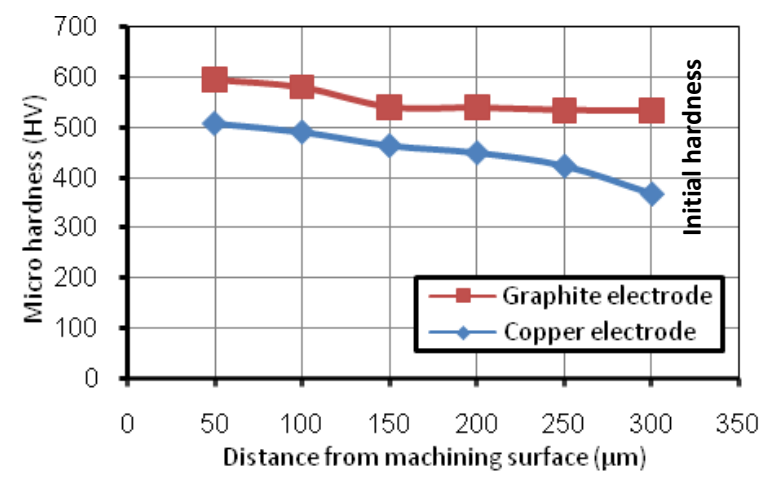

Fig.11 Variation of microhardness on cross section of EDM surface with different electrode materials, $I p=20$ A, $\beta=0.05$ Tesla, $D=0.53, P=0.8$ bar)

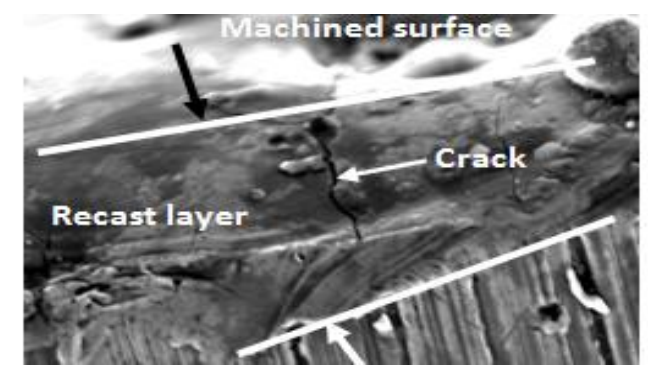

(a) Graphite electrode (20KV, 950X)

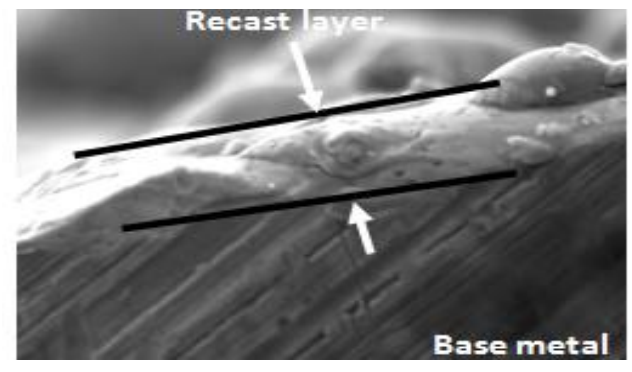

(b) Copper electrode $(20 \mathrm{KV}, 950 \mathrm{X})$

Fig.12 Typical SEM micrographs of the recast layer on the cross - section (Polarity, $(-)$; Ip $=40 \mathrm{~A}, \beta=0$ Tesla,

$$
D=0.53, P=0.8 \text { bar })
$$

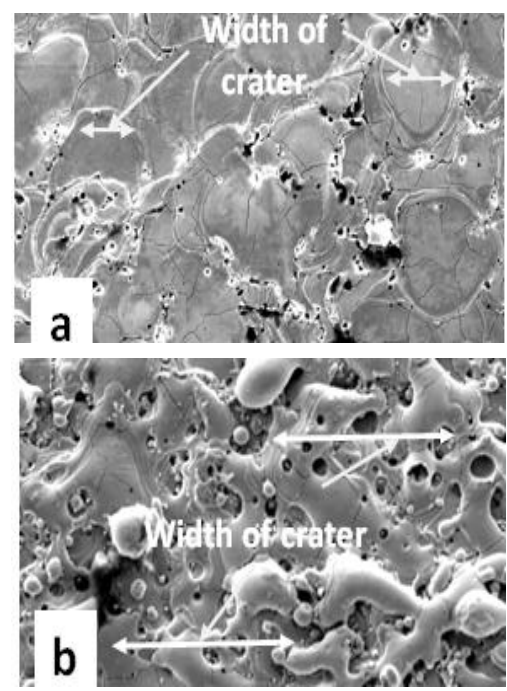

Fig. 13 SEM micrograph comparison (copper electrode) at

(a) Ip=20A, $\beta=0.05$ Tesla, $D=0.53, P=0.8$ bar, $180 \mathrm{X}$

(b) $\mathrm{Ip}=60 \mathrm{~A}, \beta=0.05$ Tesla, $\mathrm{D}=0.53, \mathrm{P}=0.8$ bar, $180 \mathrm{X}$

Figures (15-17) show a comparison of SEM micrographs at a higher energy situation $\left(\mathrm{I}_{\mathrm{p}}=60 \mathrm{~A}, \mathrm{D}=\right.$ $0.53, \mathrm{P}=0.8$ bar). As shown in these figures, the discharge craters became bigger and deeper at a large discharge energy level. Besides, there were some surface cracks on the machined surface, and the surface cracks became more obvious in conventional EDM. Since the magnetic force-assisted EDM could facilitate the expulsion of machining debris to reduce the probability of abnormal discharge, the surface cracks were relatively diminished on the machined surface.

Figure 18 shows a different cross sections of the machined surfaces for armoured steel resulted when using magnetic force-assisted EDM and conventional EDM under a peak current of $60 \mathrm{~A}$ and a duty factor of 0.53. As shown in this figure, the recast layer thickness of conventional EDM was thicker than that of the magnetic force-assisted EDM. It can be attributed to the enormous un-expelling debris that would be remelted to the machined surface to form a thicker recast layer in the conventional EDM. It is also found that the surface cracks revealed not only on the machined surface of the conventional EDM but also on the magnetic force - assisted EDM at such a high level of discharge energy (Ip: 60A, D: 0.53). In addition, the surface cracks extended to the bottom of the recast layer and revealed a trend perpendicular to the machined surface. Moreover, the surface cracks obtained by the conventional EDM were deeper and wider than that obtained by the magnetic force-assisted EDM and this result agrees with the results obtained previously by $[20,21]$. 

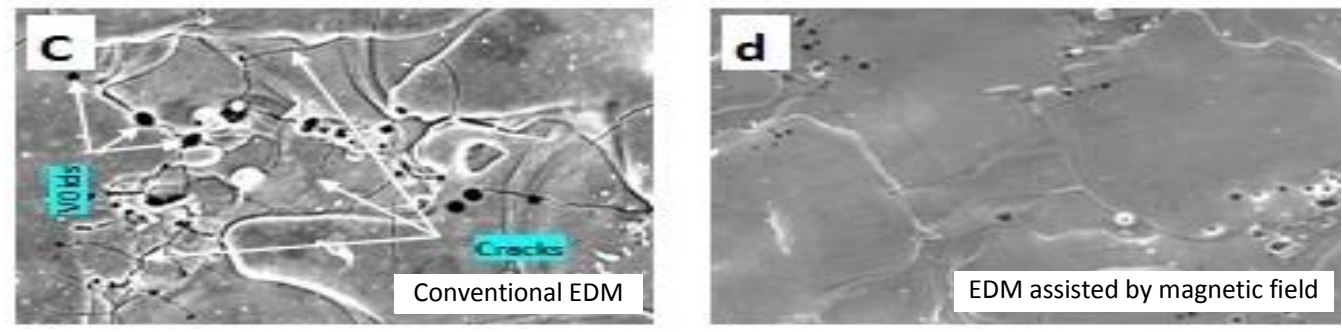

Fig. 14 Machined surface obtained by EDM assisted by magnetic field and conventional EDM, $(\mathrm{Ip}=40 \mathrm{~A}, \mathrm{D}=0.53, \mathrm{P}=0.8$ bar, Copper electrode, 500X)
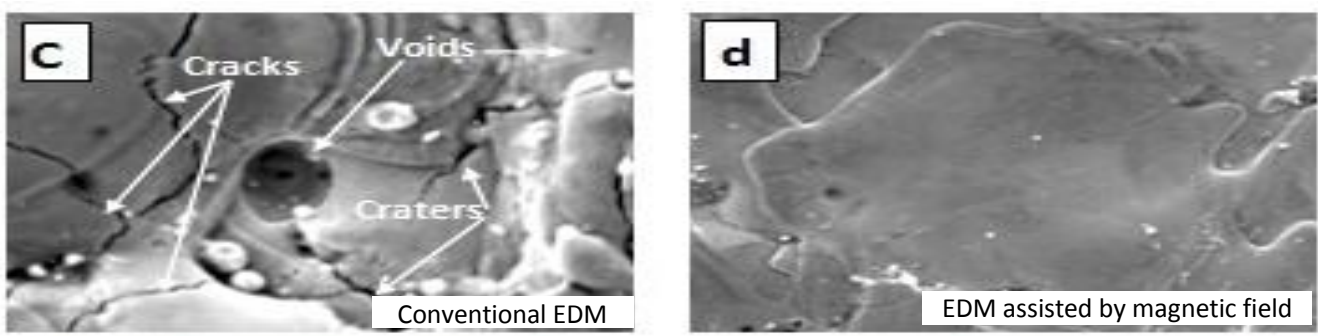

Fig.15 Machined surface obtained by EDM assisted by magnetic field and conventional EDM, $(\mathrm{Ip}=60 \mathrm{~A}, \mathrm{D}=0.53, \mathrm{P}=0.8 \mathrm{bar}$, Copper electrode, 500X)
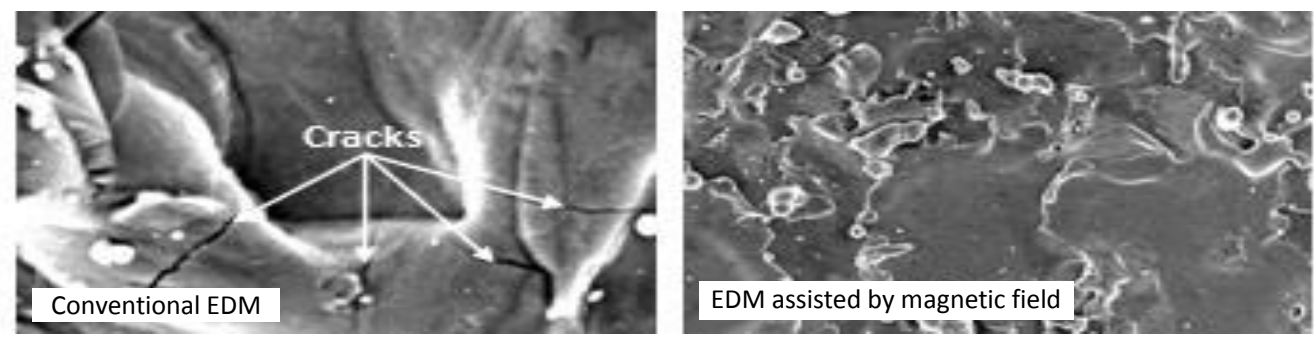

Fig.16 Machined surface obtained by EDM assisted by magnetic field and conventional EDM, $(\mathrm{Ip}=40 \mathrm{~A}, \mathrm{D}=0.53, \mathrm{P}=0.8$ bar, Graphite electrode, 500X)
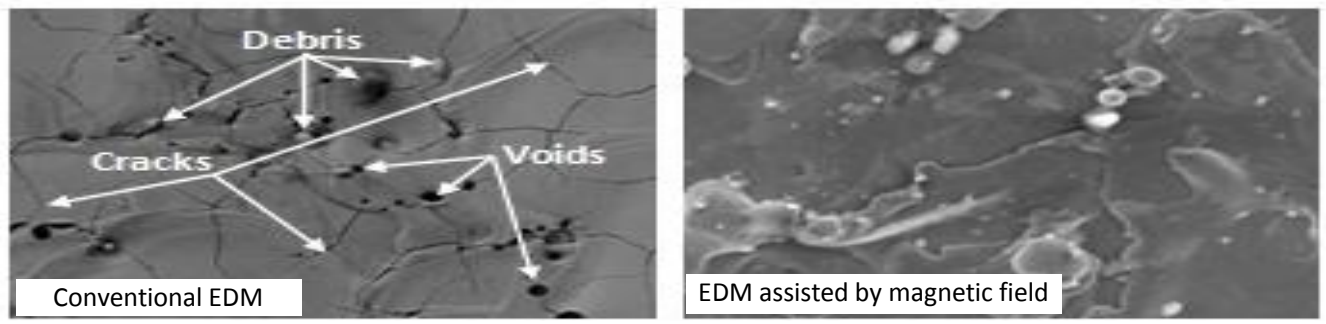

Fig.17 Machined surface obtained by EDM assisted by magnetic field and conventional EDM, $(\mathrm{Ip}=60 \mathrm{~A}, \mathrm{D}=0.53, \mathrm{P}=0.8 \mathrm{bar}$, Graphite electrode, 500X) 

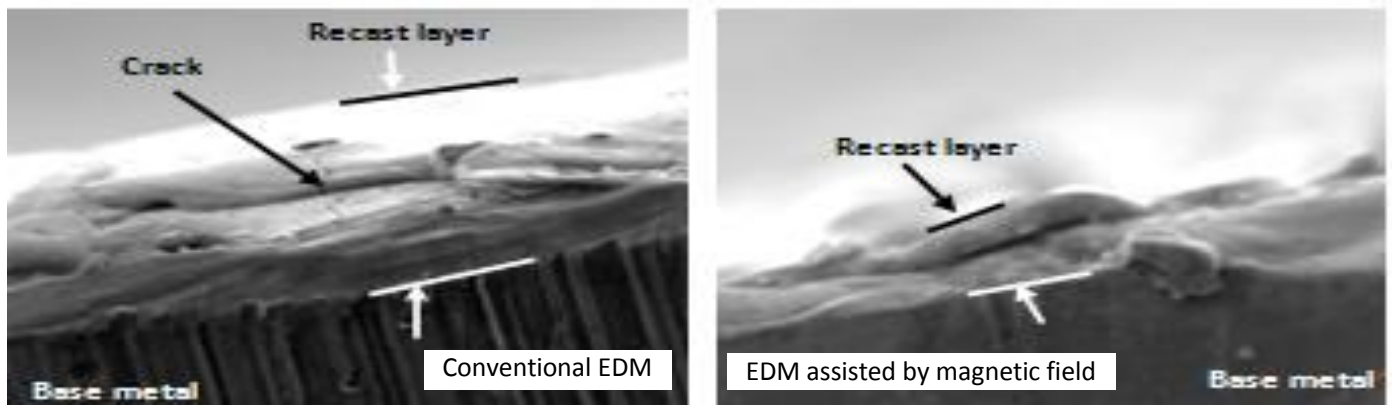

Copper electrode, $180 \mathrm{X}$
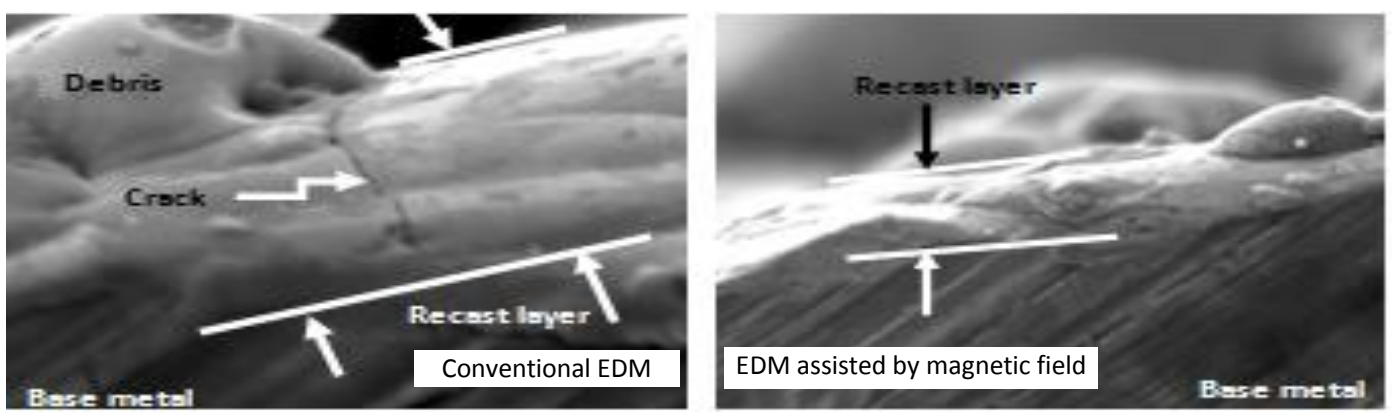

Graphite electrode, 180X

Fig.18 Cross section of machined surface obtained by EDM assisted by magnetic field and conventional EDM, (Ip $=60 \mathrm{~A}, \mathrm{D}=0.53, \mathrm{P}=0.8$ bar)

\section{CONCLUSIONS}

1. Imparting magnetic field in EDM process improves the surface quality when using copper electrode. The average surface roughness value $(\mathrm{Ra})$ with $2.4 \mu \mathrm{m}$ can be achieved.

2. Assisting EDM with magnetic field is a fruitful and beneficial process that leads to a decrease (improve) in surface roughness (Ra) significantly, as compared to that achieved with the conventional EDM of some $17 \%$ when using copper electrodes. Furthermore, an increase in surface roughness $(\mathrm{Ra})$ slightly, as compared to that achieved with the conventional EDM of some 5.22\% when using graphite electrodes.

3. Microscopic investigations revealed that the magnetic flux density is an efficient factor in improving surface texture. Moreover, the contribution of expelling machining debris using the magnetic force assisted EDM would be proven to attain a high efficiency, high precision, and high quality of surface integrity to meet the demand of modern industrial applications.

4. Microscopic investigations of the specimens revealed that the cutting surface of all specimens is harder than the bulk material because of the presence of the white layer, while the heat-affected zone is softer in quenched and tempered specimens because of over-tempered martensite.

5. The surface cracks became more obvious in the conventional EDM than that in EDM assisted by magnetic field. Since the magnetic force assisted EDM could facilitate the expulsion of machining debris to reduce the probability of abnormal electrical discharge, so the surface cracks were relatively less on the machined surface.

6. Plastic deformation, deep craters, cracks and voids have been observed at a higher peak current, higher duty factor and lower magnetic flux density.

\section{ACKNOWLEDGMENTS}

The authors wish to thank Eng. Magdi. Mohamed Ali, head and general manger of the die, forms and tool administration, production sector, in Kader Factory for Developed Industries, Arab Organization for Industrialization (AOI), Cairo, Egypt, for his great efforts and his kind support and cooperation during the experimental work of this study. 


\section{REFERENCES}

[1] J.C. Rebelo, A.Marao. Dias, D. Kremer and J.L. Lebrun, "Influence of EDM pulse energy on the surface integrity of martensitic steels.", J. Mater. Process. Technol., Vol.84, (1998), pp. 90-96.

[2] A. Abdullah, "Voltage injection and performance evaluation in EDM.", Ph.D. Thesis, The Victoria University of Manchester, (1989).

[3] H.E. DeBruijn, T.H. Delft and A. J. Pekelharig, "Effect of a magnetic field on the gap cleaning in EDM", Annals of the CIRP, Vol.27, (1978), pp.93-95.

[4] K.P. Rajurkar and S.M. Pandit, "Formation and ejection of EDM debris", Transactions of the ASME, Vol.108, (1988) pp.22-26.

[5] T. Masuzawa, X. Cui and N. Taniguchi, "Improved jet flushing for EDM", Annals of the CIRP, Vol.41, (1992), pp. 239-242.

[6] J.S. Soni, "Microanalysis of debris formed during rotary EDM of titanium alloy (Ti6Al4V) and die steel (T215Cr12)", Wear, Vol.177, (1994), pp.7179.

[7] Y.F. Lou, "The dependence of inter space discharge transitivity upon the gap debris in precision electro discharge machining", J. Mater. Process. Technol., Vol.68, (1997) pp.121-131.

[8] S. Cetin, A. Okada and Y. uno, "Effect of debris accumulation on machining speed in EDM", Int. J. Elec. Machining, Vol. 9, (2004), pp.9-14.

[9] D. Kremer, C. Lhiaubet and A. Moisan, "A study of the effect of synchronizing ultrasonic vibrations with pulse in EDM", Annals of the CIRP, Vol.40, (1991), pp. 211-214.

[10] T.B. Thoe, D.K. Aspinwall and N. Killey, "Combined ultrasonic and electrical discharge machining of ceramic-coated nickel alloy", J. Mater. Process. Technol., Vol. 92-93, (1999),pp. 323-328.

[11] Y.C. Lin, B.H. Yan and Y.S. chang, "Machining characteristics of titanium alloy (Ti-6Al-4V) using combination process of EDM with USM", J. Mater. Process. Technol., Vol.104, (2000), pp.171-177.

[12] Q.H. Zhang, J.H. Zhang, J.X. Deng, Y. Qin and Z.W. Niu, "Ultrasonic vibration electrical discharge machining in gas", J. Mater. Process. Technol., Vol.129, (2002), pp.135-138.
[13] Y.C. Lin, B.H. Yan and F.Y. Huang, "Surface modification of $\mathrm{Al}-\mathrm{Zn}-\mathrm{Mg}$ aluminum alloy using combined process of EDM with USM", J. Mater. Process. Technol., Vol. 115, (2001), 359-366.

[14] M.S. Hewidy, T.A. El-Taweel, and M.F. El-Safty "Modeling the machining parameters of wire electrical discharge machining of Inconel 601 using RSM", J. Mater. Process. Technol., Vol.169, (2005), pp.328-336.

[15] T. El-Taweel, "Multi-response optimization of EDM with $\mathrm{Al}-\mathrm{Cu}-\mathrm{Si}-\mathrm{TiC} \quad \mathrm{P} / \mathrm{M}$ composite electrode", Int. J. Adv. Manuf. Technol., Vol.44 (2009), pp.100-113.

[16] D.C Montgomery, "Design and analysis of experiments", Wiley, New York, (2001).

[17] J. Antony, "Design of experiments for engineers and scientists", Linacre House, Jordan Hill, Oxford OX2 8DP, (2003).

[18] A.B. Puri and B. Bhattacharyya, "Modeling and analysis of white layer depth in a wire-cut EDM process through response surface methodology", Int. J. Adv. Manuf. Technol., Vol.25 (2005), pp. 301-307.

[19] Yan. Cherng Lin and Ho.Shiun Lee, "Machining characteristics of magnetic force-assisted EDM", Int. J. Mach. Tools. Manuf., Vol.48, (2008), pp.1179-1186.

[20] Yan.Cherng Lin and Ho.Shiun Lee, "Optimization of machining parameters using magnetic force assisted EDM based on Taguchi method", J. Mater. Process. Technol., Manuscript Draft Number: PROTEC-D-08-00400.

[21] A. Fayed, "Machining of die materials by electric discharge machining (EDM)", M.Sc. thesis, Shebin El Kom, Faculty of Engineering, Mounifia University, 1990, Egypt.

[22] B. Philip, J. Pierre. Kruth, B. Lauwers, "Surface and sub surface quality of steel after EDM", Adv. Eng. Mater., Vol.8 (2006), N0. 1-2.

[23] H.C. Tsai, B.H. Yan and F.Y. Huang, "EDM performance of $\mathrm{Cr} / \mathrm{C}$ - based composite electrodes", Int. J. Mach. Tools. Manuf., Vol.43, (2003), pp.245 - 252.

[24] K. Kanlayasiri and S. Boonumung, “An investigation on effects of wire EDM machining parameters on surface roughness of newly developed DC 53 die steel", J. Mater. Processing Technol., Vol.187-188, (2007), pp. 26-29. 